Marquette University

e-Publications@Marquette

Psychology Faculty Research and Publications

Psychology, Department of

$1-1-1993$

\title{
Applicants' Experience of the Process of Seeking Therapy
}

Stephen M. Saunders

Marquette University, stephen.saunders@marquette.edu

Accepted version. Psychotherapy, Vol. 30, No. 4 (Winter 1993): 554-564. DOI.@ 2019 American Psychological Association. Used with permission. 


\title{
Marquette University
}

\section{e-Publications@Marquette}

\section{Psychology Faculty Research and Publications/College of Arts and Sciences}

This paper is NOT THE PUBLISHED VERSION; but the author's final, peer-reviewed manuscript. The published version may be accessed by following the link in the citation below.

Psychotherapy: Theory, Research, Practice, Training, Vol. 30, No. 4 (Winter 1993): 554-564. DOI. This article is (C) American Psychological Association and permission has been granted for this version to appear in e-Publications@Marquette. American Psychological Association does not grant permission for this article to be further copied/distributed or hosted elsewhere without the express permission from American Psychological Association.

\section{APPLICANTS' EXPERIENCE OF THE PROCESS OF SEEKING THERAPY}

\author{
Stephen M. Saunders \\ Northwestern University, Evantson, IL \\ Marquette University, Milwaukee, WI
}

\section{Acknowledgement}

This investigation was partially supported by research grant R01 MH42901 from the National Institute of Mental Health. This manuscript is based on the author's doctoral dissertation, and portions of it were presented at the 1990 annual meeting of the Society for Psychotherapy Research. The author would like to thank Kenneth I. Howard.

\section{Abstract}

Assessed the process of seeking psychotherapy, conceptualized as 4 steps: recognizing the problem; deciding therapy might help; deciding to seek therapy; and contacting the mental health system. A process of seeking therapy questionnaire was completed by 275 adult therapy applicants. It ascertained problem duration, alternative coping strategies, difficulty achieving and time needed to achieve the steps, and whether the $S$ had informal help achieving the steps. Results indicated that problems tended to be long-standing; Ss attempted a variety of coping strategies before seeking therapy; and informal help was important throughout the process. Problem recognition was the most difficult, time-consuming step. The least and most distressed Ss reported the most difficulty achieving the first 3 steps. (PsycINFO Database Record (c) 2016 APA, all rights reserved) 


\section{Introduction}

Evidence about the prevalence and treatment of mental illness suggests substantial unmet mental health need. Epidemiologic Catchment Area (ECA) program survey results indicated that the one-month prevalence rate of psychiatric disorders was $15.7 \%$ and the annual prevalence rate was $28.1 \%$ ( Regier et al., 1993). About $6 \%$ of all persons surveyed utilized specialty mental health services (the focus of this study) during a one-year period, and less than $13 \%$ of those diagnosed with a psychiatric illness did so (Regier et al., 1993).

This "service gap" ( Stefl \& Prosperi, 1985) between need and utilization of services emphasizes the importance of understanding mental health help-seeking behavior, which is conceptualized as progressing from needing to seeking services ( $c f$. Cleary, 1989). Various models of health-related behavior have been applied to mental health. For example, the Health Belief Model (Becker, 1974; Becker \& Maiman, 1983; Rosen-stock, 1974) asserts that health behaviors result from several factors, including risk-benefit analysis, symptomatology, and enabling factors, such as sociodemographic characteristics. Using such a paradigm, mental health service utilization has been found to be related to the stigma of seeking help (e.g., Farina, 1982; Stefl \& Prosperi, 1985), attitude toward services (e.g., Greenley \& Mechanic, 1976; Leaf, Bruce \& Tischler, 1986), treatment fearfulness (Kushner

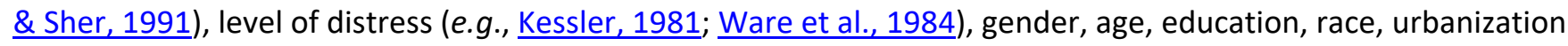
(Horgan, 1985; Taube, Kessler, \& Feuerberg, 1984; Veroff, Kulka, \& Douvan, 1981; Wells et al., 1986), and insurance coverage (Keeler et al., 1986).

In addition to examining correlates of whether or not help is sought, research has also examined the process of seeking professional or formal help for emotional distress. The various models are consistent in suggesting that the process is composed of stages, beginning with problem recognition and ending with contact with the mental health system (MHS). For example, Kadushin (1969) concluded that the process of going to a psychiatrist involved four stages: realizing there is an emotional problem, consulting one's social support network (seeking "informal" help), choosing the type of professional to consult, and selecting a specific practitioner or clinic. Kadushin reported that "friends and supporters of psychotherapy" navigated these steps more easily than others, because they were more likely to have used such services previously, to know other persons who had similar problems or had used such services, and to be relatively knowledgeable about psychological matters. In comparison, Mechanic (1976a, $\underline{b}$ ) identified three stages of the help-seeking process: the illness stage, during which the problem exists and is recognized; the illness behavior stage, during which attributions for the problem's existence are made, and various coping strategies are attempted; and the help-seeking stage, during which the individual seeks professional help.

Both Kadushin and Mechanic assert that attributing the problem to mental illness is part of the process, but Mechanic suggests that problem recognition and attribution (to mental illness) are distinct. Mechanic has presented evidence that problem recognition and problem attribution are learned responses so that individuals vary in their proclivity to do either. For example, if attributing a problem to mental illness produces "secondary pain," because one has learned that mental illness signifies personal weakness, it is more difficult and less likely ( Mechanic, 1979, 1980).

Although research has supported Mechanic's assertion that problem recognition and problem attribution are distinguishable ( Meile \& Whitt, 1981; Veroff, Douvan, \& Kulka, 1981; Veroff, Kulka, \& Douvan, 1981), it is concluded that only the former-problem recognition-is a necessary step in the process of seeking therapy. Common clinical observations and research findings are that many persons who seek mental health services have not made such an attribution; many persons seeking therapy have recognized that there is a problem, but have not attributed the symptoms or problem to mental illness (Kadushin, 1969; Whitt \& Meile, 1985;

Yokopenic, Clark, \& Aneshensel, 1983). There is evidence that making such an attribution increases the likelihood of obtaining help, but it is not a necessary step in the process of seeking help (Kessler, Brown, \& Broman, 1981; Yokopenic et al., 1983). 
It is necessary to decide that seeking professional mental help would be an appropriate way to try to solve the problem. Research has demonstrated that most psychiatrically disturbed persons do not seek such help ( Regier et al., 1993), whether they make an attribution of mental illness or not. Most persons will, however, attempt some coping strategy, such as seeking help from medical practitioners, other professionals (e.g., clergy), and nonprofessionals (Cohen \& Wills, 1985; Gourash, 1978; Horgan, 1985; Larson et al., 1988; Thoits, 1986; Veroff, Kulka, \& Douvan, 1981). More direct support for this conclusion comes from Kessler and colleagues (1981). They re-analyzed data from four large-scale surveys, and they found that about $23 \%$ of persons who made both of these decisions (i.e., recognized the emotional problem and believed that psychological help was necessary) contacted a mental health professional. In contrast, less than $30 \%$ of those who did not perceive a need for professional intervention and only $0.4 \%$ of those reporting that they did not have an emotional problem made such contact.

Summarizing the literature, it is not necessary for the individual to attribute the problem to emotional illness, but it is necessary for the person to decide that seeking mental health help would be an appropriate way to try to resolve the problem. These are the first two steps in the process.

It is apparent that seeking formal mental health help does not happen automatically after the person has decided that such help might be appropriate. Research indicates that perceived stigma about using mental health services ( Farina, 1982) and a self-reliant attitude (Warren, 1983) make deciding to seek such help less likely, regardless of one's opinion about the appropriateness of such help. Likewise, there is research evidence that receptivity to using mental health services is generally high. For example, Leaf and colleagues (1986) found that about $80 \%$ of their survey respondents had positive attitudes about using mental health services. However, despite the finding that attitude is significantly related to probability of use (Leaf et al., 1986), it is known that the majority of mentally ill persons do not seek such help. Thus it is concluded that the third step in the process is deciding to seek therapy.

Studies have suggested mat deciding to seek treatment is distinct from actually contacting a mental health professional. Phillips \& Fagan (1981) reported that almost half of the students seen at a counseling center over an 8-year period did not come to the first therapy session. Sue and colleagues (Sue, McKinney, \& Allen, 1976) reported a similar figure for community mental health centers. Garfield (1986) reviewed research on this early dropout or "no-show" phenomenon, and Schwartz \& Howard (1988) presented evidence that many such individuals have not "dropped out" of the mental health services system but, rather, have sought treatment elsewhere. It is thus concluded that the final step in the process of seeking therapy is contacting the MHS.

In summary, the process of seeking therapy is conceptualized as four consecutive steps: (1) realizing there is a problem; (2) deciding that therapy would be an appropriate way to try to solve the problem; (3) deciding to seek therapy; and (4) making contact with the MHS.

The present study also investigated how long the problem for which the person was seeking help had existed (cf. Goldberg \& Huxley, 1980). The evidence of significant unmet mental health need suggests that the time between the onset of the problem and seeking formal help for the problem might be prolonged. For example, Monroe, Simons \& Thase (1991) reported that eight months was the average time elapsed between depression onset and entering treatment.

This study also examined informal help-seeking throughout the process of formal help-seeking. Researchers have increasingly recognized that the two types of help-seeking are closely related ( $c f$. Wills, 1982). The social network may act as a facilitator in the process of seeking professional help. For example, Friedson (1960, 1970) described the "lay referral system" as an important source of influence in the process of seeking medical care, noting that process begins with the informal network and progresses "through successively more select, distant, and authoritative laymen, until the 'professional' is reached" (Friedson, 1960, p. 377). Likewise, Kadushin's 
(1969) model held that consultation with others about the problem was a distinct step in the process of seeking help, and his research supported the notion that one's social network transmits attitudes and values about the appropriateness of seeking professional help.

Members of one's social network help identify mental problems ( Gourash, 1978) and are an important source of information about coping resources. The social network can hinder recognition of the need for mental health services and may transmit attitudes contrary to utilization of these services. $\underline{\text { Horwitz }(1977 a, b}, \underline{b}, 1978)$ found that women were more likely than men to seek informal support and to self-label problems. In contrast, men spoke with relatively few persons and were more likely to have the problem labeled by spouses or employers. Further, family members were more reluctant than friends and coworkers to attribute a problem to mental illness or to refer the help seeker to a mental health professional. Ginsberg \& Brown (1982) examined why a sample of depressed females did not receive formal help, and they found that the initial consultants (e.g., friends) attributed the depression to life stress and advised against professional intervention.

Although persons who complete the process are atypical (i.e., a minority of emotionally disturbed persons actually do so), it is argued that questioning persons who successfully completed the process will further our understanding of it. Accordingly, this study expands prior work in this area by investigating the experiences of persons who recently completed the process of seeking therapy, which is conceptualized as the four steps detailed above. In particular, these individuals were asked about how difficult each step was, and how long each step took. To enhance understanding of the relationship between informal and formal help-seeking, this study investigated whether these persons had informal help in achieving the steps. Finally, this study investigated how long the problems for which therapy was being sought had existed and alternative coping strategies attempted by these individuals. Socio-demographic and clinical characteristics of the applicants were contrasted to their report of the experience of seeking therapy.

\section{Method}

\section{Dependent Variables: The Process of Seeking Therapy}

The Process of Seeking Therapy Questionnaire (PSTQ) was developed to assess therapy applicants' experience of seeking therapy. The questionnaire begins with a short paragraph describing the four-step conceptualization of the process. Respondents then indicated how long the problem for which they are seeking help has existed, and possible responses ranged from "about a week" to "more than two years." Responses were re-coded into 3 categories: about a month or less, a few months to a year, and about 2 years or more. The PTSQ also had a checklist of alternative coping strategies (Veroff, Douvan, \& Kulka, 1981) and asked respondents to indicate which they had tried. In addition, respondents were asked to whom, if anyone, they talked about the problem.

The PSTQ repeated three basic questions at each of the four steps: How difficult was the step? How long did it take? and, Who, if anyone, helped them achieve it? For the former, the six possible responses ranged from "extremely hard" (= 1) to "extremely easy" (=6). Regarding time needed, applicants were asked how long it took them to achieve that step after achieving the previous one. The six possible responses were: "right away," (=1) "about a week," "about a month," "a few months," "about a year," and "more than a year" (=6). Also, therapy applicants were asked whether anyone helped them achieve the first three steps and, at the fourth step, whether anyone referred them to the Institute.

\section{Independent Variables: Therapy Applicants' Characteristics}

PSTQs were completed by 275 persons applying for treatment at Northwestern University's Institute of Psychiatry outpatient program. The Institute is a community mental health center, and the outpatient program's overriding therapy model is long-term, psychodynamically oriented psychotherapy.

Most applicants were female (73.5\%) and most had previous psychotherapy experience (60.0\%). Respondents' age ranged from $18-62$, with a mean age of $32.0(S D=8.4)$. For purposes of data analysis, age was recategorized 
into four groups: 18-24 (13.5\%); 25-34 (56.0\%); 35-44 (20.7\%); and 45-61 (9.8\%). Level of education was recategorized into four groups: high school or less (10.9\%); some college (23.3\%); college degree (34.2\%); and, some professional or graduate school or more (31.6\%).

The applicants completed a symptom checklist, adapted from Derogatis (1977), in which they indicated to what extent a list of 61 "problems and complaints" have been bothering them on a 5-point scale ranging from "not at all" (= 1) through "extremely" (=5). The mean item endorsement was $2.7(S D=0.8)$. The therapy applicants were subgrouped into four categories (quartiles) according to their score on the symptom checklist: low distress, lowmoderate distress, high-moderate distress, and high distress.

\section{Procedure}

\section{Data collection}

The study was conducted as part of the Research Project on Long Term Psychotherapy ( Howard et al., 1988). As part of the Institute's normal policy, psychotherapy applicants are screened via standardized phone interviews to determine suitability for long-term outpatient psychotherapy, and a clinical intake interview is scheduled. Prospective clients were mailed preliminary questionnaires that became part of their clinical file. These were subsequently used as part of the research if and only if the client gave informed consent. Mail questionnaires were collected by a research assistant, who then administered the PSTQ prior to the intake interview. Thus, the PSTQ was administered at the very end of the process, immediately prior to actual contact with the MHS. Other research questionnaires were collected after the interview, including the symptom checklist questionnaire.

Statistical analyses

Preliminary chi-square analyses examining relationships among the independent variables were conducted, and one statistically significant relationship emerged. Age was related to symptomatic distress: the youngest applicants reported relatively high levels of distress whereas the oldest applicants reported relatively low levels of stress $\left(\chi^{2}[6, N=275]=19.18, p<.03\right)$. None of the other relationships were statistically significant.

Examination of the relationships between the independent variables and whether or not a particular coping strategy was attempted was conducted via chi-square analyses. Whether the relationships between the independent variables (categorical variables) and problem duration, difficulty and time needed (continuous variables) were statistically significant was determined via ANOVA.

\section{Results}

\section{Problem Duration}

Therapy applicants' responses indicated that the problems for which they were seeking help tended to be fairly long-standing: $1.8 \%$ about a week, $5.8 \%$ about a month, $19.3 \%$ a few months, $16.0 \%$ about a year, $9.1 \%$ about two years, and $48.0 \%$ more than two years (with a range of 3 to 41 years). ANOVA indicated that problem duration was not significantly associated with gender, age, education, previous therapy experience, nor symptomatic distress ( $F$-value approximately 1 ).

\section{Alternative Coping Strategies}

Therapy applicants were presented with "a list of activities which people sometimes do when they have a problem," and they were asked to indicate which they had tried. The most frequently endorsed were "tried to work it out myself" (78.9\%), "kept busy" (54.5\%), and "ignored or denied problem" (49.1\%). Other strategies attempted were: "read self-help literature" (42.5\%), "prayed" (37.5\%), "waited for it to go away" (37.5\%), "used alcohol" (25.8\%), "used prescription drugs" (12.7\%), "attended support group(s)" (11.6\%), "used illegal substances or drugs" (9.1\%), and "called crisis line or hotline" (6.5\%). Only 3 respondents (1.1\%) did not utilize one of the strategies listed. Analyses indicated that utilization of a particular strategy was not statistically related 
to any of the independent variables (gender, age, education, previous therapy experience, or symptomatic distress).

As noted above, therapy applicants indicated whether anyone helped them achieve the various steps in the process: $156(56.7 \%)$ had help deciding there was a problem; $179(65.1 \%)$ had help deciding to seek therapy; 153 (55.6\%) had help deciding to seek therapy; and 198 (72.0\%) had been referred to the Institute.

\section{Difficulty Associated with the Process}

Table 1 summarizes the therapy applicants' endorsement of the PSTQ questions ascertaining how difficult it was to achieve the various steps. It can be seen that the first step in the process was the most difficult and that subsequent steps got progressively easier. Over half (56\%) of the applicants stated that realizing there was a problem was at least somewhat hard, whereas almost $64 \%$ felt that the last step, calling for an appointment, was at least somewhat easy.

TABLE I. Difficulty Associated with the Steps: "How Difficult Was It for You to ... (do the following)?"

\begin{tabular}{|l|l|l|l|l|}
\hline & $\begin{array}{l}\text { ".. Realize There Is } \\
\text { a Problem" }\end{array}$ & $\begin{array}{l}\text { ".. Decide Therapy } \\
\text { Might Help" }\end{array}$ & $\begin{array}{l}\text { "... Decide to Seek } \\
\text { Therapy" }\end{array}$ & $\begin{array}{l}\text { "... Call for an } \\
\text { Appointment" }\end{array}$ \\
\hline & $\mathrm{n}(\%)$ & $\mathrm{n}(\%)$ & $\mathrm{n}(\%)$ & $\mathrm{n}(\%)$ \\
\hline Extremely hard & $36(13.1 \%)$ & $23(8.4 \%)$ & $21(7.6 \%)$ & $14(5.1 \%)$ \\
\hline Very hard & $44(16.0 \%)$ & $18(6.5 \%)$ & $21(7.6 \%)$ & $21(7.6 \%)$ \\
\hline Somewhat hard & $74(26.9 \%)$ & $69(25.1 \%)$ & $66(24.0 \%)$ & $65(23.6 \%)$ \\
\hline Somewhat easy & $51(18.5 \%)$ & $72(26.2 \%)$ & $78(28.4 \%)$ & $64(23.3 \%)$ \\
\hline Very easy & $42(15.3 \%)$ & $56(20.4 \%)$ & $55(20.0 \%)$ & $71(25.8 \%)$ \\
\hline Extremely easy & $28(10.2 \%)$ & $37(13.5 \%)$ & $34(12.4 \%)$ & $40(14.5 \%)$ \\
\hline
\end{tabular}

The applicants' rating of how difficult it was to achieve the steps was statistically unrelated to their gender, age, education level, or previous therapy experience. At the second step, deciding therapy might be appropriate, the relationship between social support and difficulty was significant: applicants who talked to someone $(M=3.6)$ reported greater difficulty than their peers $(M=4.2), t(272)=3.19, p<.01$. This relationship trend held for the other steps, but was not statistically significant.

Symptomatic distress at the time of the interview was related to difficulty experienced achieving the first three steps. At all three steps, there was a curvilinear relationship between level of distress and difficulty experienced. The least $(M=3.4,3.8,3.8)$ and most $(M=3.8,4.3,4.2)$ distressed applicants reported significantly more difficulty achieving the first three steps than did the low-moderate $(M=3.1,3.6,3.6)$ and high-moderate $(M=$ 3.1, 3.6, 3.6) distressed applicants: Step 1, F = 3.62, $p<.02$; Step 2, $F(3,268)=4.06, p<.01$; Step 3, $F(3,268)=$ $3.38, p<.02$. The trend held for the fourth step but was not statistically significant.

\section{Time Needed to Complete the Steps}

Table 2 shows the applicants' ratings of how long it took to achieve the steps. The first step in the process took the longest to achieve, and subsequent steps were achieved relatively more quickly.

TABLE 2. Time Needed to Achieve the Steps: "How Long Did It Take for You to ... (do the following)?"

\begin{tabular}{|l|l|l|l}
\hline "... Realize There Is a & $\begin{array}{l}\text { "... Decide Therapy } \\
\text { Problem" }\end{array}$ & $\begin{array}{l}\text { "... Decide to Seek } \\
\text { Therapy" }\end{array}$ & $\begin{array}{l}\text { "... Call for an } \\
\text { Appointment" }\end{array}$ \\
\hline
\end{tabular}




\begin{tabular}{|l|l|l|l|l|}
\hline & $\mathrm{n}(\%)$ & $\mathrm{n}(\%)$ & $\mathrm{n}(\%)$ \\
\hline Right away & $38(13.8 \%)$ & $48(17.5 \%)$ & $73(26.5 \%)$ & $107(38.9 \%)$ \\
\hline $\begin{array}{l}\text { About a } \\
\text { week }\end{array}$ & $9(3.3 \%)$ & $17(6.2 \%)$ & $38(13.8 \%)$ & $58(21.1 \%)$ \\
\hline $\begin{array}{l}\text { About a } \\
\text { month }\end{array}$ & $28(10.2 \%)$ & $41(14.9 \%)$ & $56(20.4 \%)$ & $51(18.5 \%)$ \\
\hline $\begin{array}{l}\text { A few } \\
\text { months }\end{array}$ & $66(24.0 \%)$ & $79(28.7 \%)$ & $51(18.5 \%)$ & $33(12.0 \%)$ \\
\hline \begin{tabular}{l} 
About a year \\
\hline $\begin{array}{l}\text { More than a } \\
\text { year }\end{array}$
\end{tabular} & $36(13.1 \%)$ & $27(9.8 \%)$ & $17(6.2 \%)$ & $3(1.1 \%)$ \\
\hline
\end{tabular}

The therapy applicants' endorsement of how long it took to achieve any of the four steps was unrelated to gender, previous therapy experience, and symptomatic distress. Time needed to recognize the problem (step 1) was unrelated to the applicants' age, but was significantly related to education and to whether they talked to someone. The better-educated applicants $(M$ (some graduduate school $)=4.3 ; M($ college degree $)=4.7)$ tended to take longer to achieve this step than the lesser educated applicants ( $M$ (high school or less) $=3.9 ; M$ (some college $)=3.7), \mathrm{F}(3,271)=4.54, p<.01$. Applicants who spoke to another person about this step $(M=4.5)$ reported taking significantly longer to achieve it than those who did not consult with another person $(M=3.9)$, $\mathrm{t}(273)=2.87, p<.01$.

The time needed to achieve step 2 was not related to whether they talked to someone about the step or their education level, but was curvilinearly related to age: the 35-44-year-old respondents $(M=3.2)$ reported that they needed less time to achieve the step than their younger $(M(18-24)=3.7 ; M(25-34)=3.9)$ and older $(M(45-$ $61)=4.3$ ) counterparts, $\mathrm{F}(3,271)=3.51, p<.02$.

Time needed to achieve step 3 was unrelated to age or education, but was related to whether the applicant had assistance. Those who talked with someone about the step $(M=2.8)$ took significantly less time to achieve it than those who did not $(M=3.4), t(273)=2.51, p<.02$.

\section{Association between Difficulty and Time}

Table 3 shows the results of Pearson product-moment correlation analyses examining the relationship between difficulty and time needed at the various steps. It can be seen that difficulty at any particular step was fairly highly correlated to difficulty at other steps, especially the subsequent or prior one. The applicants' reports of time needed to achieve the step was statistically related to their rating of the difficulty at that step. Finally, the time needed to achieve any particular step tended to be related to the time needed at other steps, although the variance accounted for by this association was often small.

TABLE 3. Correlations between Difficulty and Time Needed at the Steps

\begin{tabular}{|l|l|l|l|l|l|l|l|}
\hline & Step 1 & Step 2 & Step 3 & Step 4 & Step 1 & Step 2 & Step 3 \\
\hline & Difficulty & Difficulty & Difficulty & Difficulty & Time & Time & Time \\
\hline Step 2 Difficulty & $.65^{* *}$ & & & & & & \\
\hline Step 3 Difficulty & $.60^{* *}$ & $.80^{* *}$ & & & & & \\
\hline Step 4 Difficulty & $.36^{* *}$ & $.53^{* *}$ & $.65^{* *}$ & & & & \\
\hline Step 1 Time & $-.26^{* *}$ & $-.14^{*}$ & -.11 & -.06 & & & \\
\hline Step 2 Time & $-.15^{*}$ & $-.27^{* *}$ & $-.19^{* *}$ & $-.22^{* *}$ & $.29 * *$ & & \\
\hline
\end{tabular}




\begin{tabular}{|l|l|l|l|l|l|l|l|}
\hline Step 3 Time & $-.18^{*}$ & $-.16^{* *}$ & $-.24^{* *}$ & $-.28^{* *}$ & $.12^{*}$ & $.41^{*}$ & \\
\hline Step 4 Time & -.04 & -.10 & $-.13^{*}$ & $-.28^{* *}$ & $.12^{*}$ & $.31^{*}$ & $.59^{* *}$ \\
\hline
\end{tabular}

$* p<.05$.

$* * p<.01$.

\section{Discussion}

The current national concerns about health care reform directly concern mental health service providers. By examining the process that psychotherapy applicants went through to enter the system, the current article provides information that can be applied to the issue of mental health services accessibility, supplementing information available about barriers to and problems of access (e.g., Office of Technology Assessment, 1991). In other words, this article provides information about that minority of emotionally disturbed persons that does seek mental health services. This article focused on the duration of the problem(s) for which help was being sought, the difficulty and time expended to negotiate the process of obtaining therapy, and the extent and effect of informal help-seeking on professional help-seeking.

One of the purposes of the study was to assess the validity of this conceptualization of the process of seeking therapy. In general, the results suggest that these therapy applicants were capable of distinguishing the steps, evinced by their report of variable difficulty and time needed to accomplish them. For example, 53 of the therapy applicants who reported that step 1 was relatively difficult found the next step relatively easy, whereas 9 who reported that the first step was easy reported that the next step was difficult. Thirty therapy applicants "switched" in this manner at the next step, and 64 at the final step. Altogether, 130 of the therapy applicants found some of the steps in the process of seeking therapy to be relatively easy and others to be relatively difficult. Likewise, although some respondents reported that they had decided there was a problem and decided that seeking therapy would be appropriate simultaneously, over three-fourths needed at least a few months to do so suggesting that they are distinct. Likewise, over half of the therapy applicants needed at least a month to decide to seek therapy after concluding that it might help.

Other research is consistent with the impression, from this data, that the steps are distinct. For example, Leaf et al. (1986) reported that $80 \%$ of ECA respondents had positive attitudes toward mental health services, yet about $80 \%$ of the diagnosable population do not seek such treatment ( Shapiro et al., 1984 ). Likewise, Veroff, Kulka, \& Douvan (1981) found that respondents' hypothetical willingness to use professional services was "only slightly related to indicators of the actual use" (p. 68).

The results suggested that the problems for which therapy applicants seek help tend to be of long-standing nature. Similarly, Monroe et al. (1991) reported that the average time between the onset of depression and treatment entry for a sample of 61 outpatients was greater than 8 months. This suggests that therapy applicants do not automatically enter treatment when bothered by minor problems, a stigmatizing notion that disparages the relevance of professional intervention. In contrast, these results suggest that seeking therapy is just one of a multitude of coping strategies employed: $99 \%$ of these applicants had attempted alternative coping strategies prior to seeking professional help ( $c f$. Mechanic, 1976). The most common coping attempts were seeking informal help and trying to solve the problem, but passive strategies, such as keeping busy and ignoring or denying the problem, were also frequently endorsed (Veroff, Kulka, \& Douvan, 1981). The coping attempts were similar to those of persons with problems in the general population (Veroff, Douvan, \& Kulka, 1981; Veroff, Kulka, \& Douvan, 1981).

The results indicate that such coping attempts are related to the process as a whole. For example, at each of the

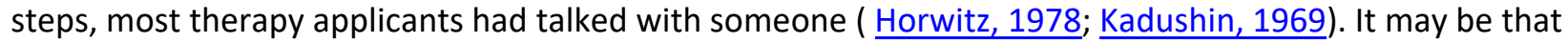
alternative coping strategies are exhausted prior to seeking therapy, and that these failed strategies contribute to the speed and difficulty with which the steps are achieved (Whitt \& Meile, 1985). Further investigation should 
attempt to clarify the relationship between such coping strategies and the steps in the process, as these results suggest that they are an integral part of the process.

These results indicated that the first step, problem recognition, is the most difficult and time-consuming. This step was particularly difficult for the least and the most distressed therapy applicants, with the latter reporting particular difficulty. In part, this suggest that there is an optimal level of distress related to ease of problem recognition: distress must be high enough for problem recognition, to begin the process of seeking help ( Kessler, Reuter, \& Greenley, 1979; Ware et al., 1984). The finding that the most highly distressed therapy applicants had the most difficulty recognizing the problem suggests that not recognizing the problem caused the problem to be exacerbated. Alternatively, defensive mechanisms such as denial and repression (which would obviously inhibit problem recognition) may come into play more readily for some persons or some presenting problems.

The time needed to recognize the problem was related to education and utilization of social support. The most educated and those who talked with others about this step took significantly longer to achieve it than their counterparts. These results seem inconsistent with the plethora of research showing that education is related to both the probability of utilizing mental health services (e.g., Taube, Kessler, \& Feuerberg, 1984) and positive attitudes toward mental health services (e.g., Fischer \& Cohen, 1972; Leaf et al., 1987). While it is noted that these therapy applicants, as a whole, were fairly well-educated (most had at least some college experience), the relationship is nonetheless paradoxical and needs further exploration. One interpretation is that these results reflect a greater self-help or self-reliant attitude, and perhaps a reliance on longer-lasting or more persistent alternative coping attempts, by better educated persons. This interpretation is consistent with the finding that persons who obtained informal help when trying to achieve this step took longer to do so.

In any case, these results strongly suggest that a primary barrier to receiving mental health care for emotional problems is recognizing the problem, and more research is needed to determine how this barrier might effectively be breached, as it was by these applicants. Perhaps focusing on those individuals who do not find this step particularly difficult would prove fruitful. Research might focus on the nature of the presenting problem as a determinant of the ease with which it is recognized. It seems likely that some problems are easier to recognize than others, and that this relationship would, in turn, be influenced by other variables such as gender, educational status, marital status, and level of distress.

In contrast to the initial one, the majority of respondents indicated that the latter three steps were relatively easy. The second and third steps, deciding that therapy might help and deciding to seek therapy, were particularly difficult for the least and most distressed applicants. Again, one interpretation of these data is that distress must be high enough for some persons to make these two decisions, but that experiencing difficulty making them may cause the problem and associated distress to be intensified. Consistent with these results, Kushner \& Sher (1989) reported that fear of mental health treatment and psychiatric distress were positively associated. There seems to be an "approach-avoidance" phenomenon, familiar to many clinicians, characterizing the balance between distress and help-seeking, as suggested by Mechanic $(1979,1980)$ who spoke of the "secondary pain" associated with mental health help-seeking.

Social support at the second step, deciding that therapy might help, was related to having greater difficulty achieving the step. The directionality of this relationship is not discernible with this data, but one interpretation is that persons who had difficulty admitting or deciding that seeking therapy would be appropriate were more likely to seek informal help at this step. Alternatively, seeking social support might make deciding therapy might help more difficult ( Ginsberg \& Brown, 1982; Horwitz, 1978). These results indicate that the relationship between informal and formal help-seeking is multi-faceted and complex. 
For these applicants, the latter three steps, and in particular the latter two, were achieved relatively quickly. Time needed to decide that therapy might help was related to age, as therapy applicants who were 45 and older or younger than 34 reported requiring more time to do so. Research has established that older and younger persons are less likely to seek mental health services (Shapiro et al., 1984), and these results suggest that this is at least partly due to the attitude that such services are appropriate. Intertestingly, the relationship between social support and time needed to achieve the third step, deciding to seek therapy, was opposite of the relationship at the first step, recognizing that there was a problem. That is, respondents who talked to someone about the step took less time to achieve it. The complexity of the relationship between seeking informal and formal help is attested to by these results, and further work in this area is warranted.

It was expected that previous therapy experience would be related to the process of seeking therapy, but at all the steps it was not. Asking simply whether a client had previous therapy may be too nonspecific. It may be relevant to discern what type of therapy was previously attended, what the presenting problems were, how long it lasted, and what the outcome was. Further research might, for example, categorize persons who have had previous therapy according to whether they received an adequate "dose" (cf. Howard et al., 1988). In any event, this finding requires further examination. In addition, the ancillary finding that previous therapy experience was unrelated to any demographic or clinical characteristics of the clients is interesting and requires exploration.

These results support the implication, from epi-demiological data suggesting significant unmet need, that seeking professional mental health help is a fairly long and difficult process. Extrapolating from these results, it might be argued that there are numerous individuals in the population who are at various steps in the process but have yet to complete the process. It may be that many diagnosable persons who are not seeking mental health treatment are at one of the steps in the process and are having difficulty (or are taking a long time) achieving the next. Likewise, it might be anticipated that some people begin and prematurely terminate the process repeatedly. This study forced the respondents to consider the process to be sequential but, given the low rate of utilization of mental health services, such "false starts" and iterations might be predicted (cf. Kadushin, 1969). Such an extrapolation must be done very cautiously, however. It is unknown whether persons who seek psychotherapy, as the subjects in this study did, are in some way distinct from persons who do not. This study may be, at best, only generalizable to psychotherapy applicants. The generalizability of these findings is an empirical issue requiring further study.

That therapy applicants can discriminate between the various steps and decisions of the process is an important finding that may help future intervention efforts that seek to reduce the service gap. With respect to community intervention and mental health services, the present study helps discriminate or pinpoint the steps at which the barriers to seeking treatment for emotional distress occur. These results indicate that the most difficult aspect of the process is recognizing the existence of the problem, which even persons with previous therapy experience tended to find difficult. Deciding that therapy might help was less difficult for these respondents, but tended to take a long time to achieve. In contrast, once the respondents achieved the second step, the remainder of the process was fairly quick and easy.

According to the present model, the NIMH Depression Awareness, Recognition and Treatment (DART) project focuses on the first two steps in the process of seeking psychotherapy. It is intended to enhance both professionals' and the general public's ability to recognize depression and to increase their understanding that it is a serious and treatable problem ( Regier, Hirschfeld et al., 1988). These results suggest that such a focus is correct and that, in particular, focusing on helping individuals recognize emotional disorders is important.

It has been noted that overcoming barriers to treatment is part of the change process of psychotherapy. Kadushin (1969) stated "The very process of deciding to go to a psychiatrist or psychotherapist is 'therapeutic' and much that must ultimately change as a result of therapy begins to change during the decision to seek help" (p. 15). Accordingly, the relationship between the process of seeking therapy and the process and outcome of 
therapy itself might be investigated. For example, research might investigate whether the difficulty experienced seeking therapy influences treatment compliance or premature termination. On the one hand, difficulty experienced in the process of seeking therapy might forebode difficulty in the therapy process itself. Alternatively, difficulty overcoming barriers to obtaining treatment may increase the likelihood that a client will persevere despite barriers experienced in that treatment.

\section{REFERENCES}

Becker, M. H. (1974). The health belief model and personal health behavior. Thorofare, NJ: Slack.

Becker, M. H., \& Maiman, L. A. (1983). Models of health-related behavior. In D.Mechanic (Ed.), Handbook of health, health care, and the health professions (pp. 539-568). New York: Free Press.

Cleary, P. D. (1989). The need and demand for mental health services. In C. A.Taube, D.Mechanic, and A.

A.Hohmann (Eds.), The future of mental health services research (DHHS Publication No. ADM 89-1600, pp. 161-184). Rockville, MD: National Institute of Mental Health.

Cohen, S., \& Wills, T. A. (1985). Stress, social support, and the buffering hypothesis. Psychological Bulletin, 98, 310-357.

Farina, A. (1982). The stigma of mental disorder. In A. G.Miller (Ed.), In the eye of the beholder (pp. 305-363). New York: Praeger.

Fischer, E. H., \& Cohen, S. L. (1972). Demographic correlates of attitude toward seeking professional psychological help. Journal of Consulting and Clinical Psychology, 35, 79-90.

Friedson, E. (1960). Client control of medical practice. American Journal of Sociology, 65, 374-382.

Friedson, E. (1970). Profession of medicine. New York: Dodd, Mead.

Ginsberg, S. M., \& Brown, G. W. (1982). No time for depression: A study of help-seeking among mothers of preschool children. In D.Mechanic (Ed.), Symptoms, illness behavior, and help-seeking (pp. 87-114). New York: Prodist.

Goldberg, D., \& Huxley, P. (1980). Mental illness in the community: The pathway to psychiatric care. New York: Tavistock.

Gourash, N. (1978). Help-seeking: A review of the literature. American Journal of Community Psychology, 6, 413423.

Greenley, J. R., \& Mechanic, D. (1976). Social selection in seeking help for psychological problems. Journal of Health and Social Behavior, 17, 249-262.

Morgan, C. M. (1985). Specialty and general ambulatory mental health services. Archives of General Psychiatry, $42,565-572$.

HoRwrrz, A. (1977a). Social networks and pathways into psychiatric treatment. Social Forces, 56, 86-105.

Horwttz, A. (1976). The pathways into psychiatric treatment: Some differences between men and women. Journal of Health and Social Behavior, 18, 169-178.

HoRwrrz, A. (1978). Family, kin and friend networks in psychiatric help-seeking. Social Science and Medicine, 12, 297-304.

Howard, K. I. (1988). The psychotherapeutic service delivery system. Paper presented the meeting of the Society for Psychotherapy Research, Santa Fe, NM, June.

Howard, K. I., Davison, C. V., O’Mahoney, M., \& Orunsky, D. E. (1988). Long-term psychotherapy: Patients, processes and outcome. NIMH Grant Proposal (Available from K. I. Howard, Northwestern University, Evanston, IL 60208).

Howard, K. I., Kopta, S. M., Krause, S. M., \& Orlinsky, D. E. (1986). The dose-effect relationship in psychotherapy. The American Psychologist, 41, 159-164.

Kadushin, C. (1969). Why people go to psychiatrists. New York: Atherton.

Keeler, E. B., Wells, K. B., Manning, W. G., Rumpel, J. D., \& Hanley, J. M. (1986). The demand for episodes of mental health services. (National Institute of Mental Health Publication R-3432). Santa Monica, CA: Rand Corporation.

Kessler, R. C. (1981). Reply to Gove and Swafford. Social Forces, 59, 1291-1296. 
Kessler, R. C., Brown, R. L., \& Broman, C. L. (1981). Sex differences in psychiatric help-seeking: Evidence from four large-scale surveys. Journal of Health and Social Behavior, 22, 49-64.

Kessler, R. C., Reuter, J. A., \& Greenley, J. R. (1979). Sex differences in the use of psychiatric outpatient facilities. Social Forces, 58, 557-571.

Kushner, M. G., \& Sher, K. J. (1989). Fear of psychological services and its relation to service utilization. Professional Psychology: Research and Practice, 20, 251-257.

Kushner, M. G., \& Sher, K. J. (1991). The relation of treatment fearfulness and psychological service utlization: An overview. Professional Psychology: Research and Practice, 22, 196-203.

Larson, D. B., Hohmann, A. A., Kessler, L. G., Meador, K. G., Boyd, J. H., \& McSherry, E. (1988). The couch and the cloth: The need for linkage. Hospital and Community Psychiatry, 39, 1064-1069.

Leaf, P. J., Bruce, M. L., \& Tischler, G. L. (1986). The differential effect of attitudes on the use of mental health services. Social Psychiatry, 21, 187-192.

Leaf, P. J., Livingston, M. M., Tischler, G. L., \& Holzer, C. E. (1987). The relationship between demographic factors and attitudes towards mental health services. Journal of Community Psychology, 15, 275-284.

Mechanic, D. (1976a). Illness, illness behavior, and help-seeking: Implications for increasing the responsiveness of health services. In D.Mechanic (Ed.), The growth of bureaucratic medicine (pp. 161-176). New York: Wiley Interscience.

Mechanic, D. (1976b). Stress, illness and illness behavior. Journal of Human Stress, 2, 2-6.

Mechanic, D. (1979). Development of psychological distress among young adults. Archives of General Psychiatry, $36,1233-1239$.

Mechanic, D. (1980). Mental health and social policy (2nd ed.). Englewood Cliffs, NJ: Prentice-Hall.

Meile, R. L., \& Whitt, H. P. (1981). Cultural consensus and definition of mental illness. Social Science and Medicine Part A: Medical Sociology, 15, 231-242.

Monroe, S. M., Simons, A. D., \& Thase, M. E. (1991). Onset of depression and time to treatment entry: Roles of life stress. Journal of Consulting and Clinical Psychology, 59, 566-573.

Phillips, E. L., \& Pagan, P. J. (1981). Attrition: Focus on the intake and first therapy interviews. Paper presented at the annual convention of the American Psychological Association, Washington, DC, August.

Regier, D. A., Boyd, J. H., Burke, J. D., Rae, D. S., Myers, J. K., Kramer, M., Robins, L. N., George, L. K., Karno, M., \& Locke, B. Z. (1988). One-month prevalence of mental disorders in the United States. Archives of General Psychiatry, 45, 977-986.

Regier, D. A., Hirschfeld, R. M. A., Goowdin, F. K., Burke, J. D., Lazar, J. B., \& Lewis, L. J. (1988). The NIMH Depression Awareness, Recognition and Treatment Program: Structure, aims and scientific basis. American Journal of Psychiatry, 145, 1351-1357.

Regier, D. A., Narrow, W. E., Rae, D. S., Manderscheid, R. W, Locke, B. Z., \& Goowdin, F. K. (1993). The de Facto US mental and addictive disorders service system. Archives of General Psychiatry, 50, 85-94.

Rosen-stock, I. M. (1974). Historical origins of the Health Belief Model. Health Education Monographs, 2, 328335.

Shapiro, S., Skinner, E. A., Kessler, L. G., Von Korff, M., German, P. S., Tischler, G. L., Leaf, P. J., Benham, L., Cottler, L., \& Regier, D. A. (1984). Utilization of health and mental health services: Three epidemiologic catchment area sites. Archives of General Psychiatry, 41, 971-978.

Stefl, M. E., \& Prosperi, D. C. (1985). Barriers to mental health service utilization. Community Mental Health Journal, 21, 167-178.

Sue, S., Mckinney, H. L., \& Allen, D. B. (1976). Predicators of the duration of therapy for clients in the community mental health system. Community Mental Health Journal, 12, 365-375.

Taube, C. A., Kessler, L. G., \& Feuerberg, M. (1984). Utilization and expenditures for ambulatory mental health care during 1980. National medical care utilization and expenditure survey, Data Report 5. U.S. Department of Health and Human Services.

U.S. Congress/Office of Technology Assessment. (1991). Adolescent health: Vol. 3. Crosscutting issues in the delivery of health and related services. (OTAQ-H-446). Washington DC: Government Printing Office. 
Veroff, J., Douvan, E., \& Kulka, R. A. (1981). The Inner-American: A self-portrait from 1957 to 1976. New York: Basic.

Veroff, J., Kulka, R. A., \& Douvan, E. (1981). Mental health in American: Patterns of help-seeking from 1957 to 1976. New York: Basic.

Ware, J. E., Manning, W. G., Duan, N., Wells, K. B., \& Newhouse, J. P. (1984). Health status and use of outpatient mental health services. American Psychologist, 39, 1090-1100.

Warren, L. W. (1983). Male tolerance of depression: A review with implications for psychotherapy. Clinical Psychology Review, 3, 147-156.

Wells, K. B., Manning, W. G., Duan, N., Newhouse, J. P., \& Ware, J. E. (1986). Socio-demographic factors and the use of outpatient mental health services. Medical Care, 24, 75-85.

Whttt, H. P., \& Meile, R. L. (1985). Alignment, magnification and snowballing processes in the definition of symptoms of mental illness. Social Forces, 63, 682-697.

Wills, T. A. (1982). Basic processes in helping relationships. New York: Academic.

Yokopenic, P. A., Clark, V. A., \& Aneshensel, C. S. (1983). Depression, problem recognition and professional consultation. Journal of Nervous and Mental Disorders, 171, 15-23. 